\title{
Segmental lumbar mobility in individuals with low back pain: in vivo assessment during manual and self-imposed motion using dynamic MRI
}

\author{
Kornelia Kulig*1, Christopher M Powers ${ }^{1}$, Robert F Landel ${ }^{1}$, \\ Hungwen Chen ${ }^{1}$, Michael Fredericson ${ }^{2}$, Marc Guillet ${ }^{2}$ and Kim Butts ${ }^{3}$
}

\begin{abstract}
Address: ${ }^{1}$ Department of Biokinesiology and Physical Therapy, University of Southern California, 1540 East Alcazar St., CHP-155, Los Angeles, CA 90089, USA, ${ }^{2}$ Department of Functional Restoration, Division of Sports Medicine, Stanford University, Stanford, CA 94305, USA and ${ }^{3}$ Department of Radiology, Stanford University, Stanford, CA 94305, USA
\end{abstract}

Email: Kornelia Kulig* - kulig@usc.edu; Christopher M Powers - powers@usc.edu; Robert F Landel - rlandel@usc.edu;

Hungwen Chen - hungwenchen@hotmail.com; Michael Fredericson - mfred2@stanford.edu; Marc Guillet - marc@agilept.com;

Kim Butts - kimbutts@stanford.edu

* Corresponding author

Published: 29 january 2007

BMC Musculoskeletal Disorders 2007, 8:8 doi:I0.1186/147I-2474-8-8

This article is available from: http://www.biomedcentral.com/I47/-2474/8/8

(c) 2007 Kulig et al; licensee BioMed Central Ltd.

This is an Open Access article distributed under the terms of the Creative Commons Attribution License (http://creativecommons.org/licenses/by/2.0), which permits unrestricted use, distribution, and reproduction in any medium, provided the original work is properly cited.
Received: 7 June 2006

Accepted: 29 january 2007

\begin{abstract}
Background: Altered spinal mobility is thought to be related to current or past episodes of low back pain; however evidence of that relationship in younger subjects has not been established. The purpose of this study was to compare lumbar segmental mobility in asymptomatic and symptomatic subjects during posterior to anterior (PA) manual spinal mobilization and a self-initiated prone press-up (PU) maneuver. We hypothesized that persons with central low back pain would have an altered lumbar segmental mobility pattern compared to those without pain.

Method: Forty-five individuals (age $32.1 \pm 8.5$ ) with non-specific low back pain and 20 persons (age $31 . I \pm 7.0$ ) without low back pain participated. Each subject underwent dynamic imaging of the lumbar spine during a PA mobilization procedure and while performing a PU. Segmental motion was quantified as the change in the intervertebral angle between the resting and end-range vertebral positions.
\end{abstract}

Results: The symptomatic group had a larger percentage of subjects with evidence of single level segmental hypermobility than the asymptomatic group during the PA $(40.0 \%$ vs. $5 \%)$ and PU $(26.7 \%$ vs. $15 \%$ ) procedures. Single lumbar motion-segment analysis revealed hyper-mobility in symptomatic subjects at L5 $-\mathrm{SI}($ Chi-square $=10.0, \mathrm{p} \leq 0.01)$ and L4 - L5 (Chi-square $=4.18, \mathrm{p} \leq$ 0.05) during the PA test.

Conclusion: Persons with non-specific low back pain have a tendency to demonstrate single level lumbar segmental hypermobility when compared to age specific asymptomatic subjects.

\section{Background}

Back pain and its association with altered functional ability can significantly affect an individual's quality of life
[1,2]. Prevalence of low back pain throughout the lifespan has been reported to be between 13 and 85\% [3-7]. The point prevalence of back pain varies with age [7]. Back 
pain is considered the plague of middle-age; however, it can certainly begin its manifestation in the younger individuals. [8] Even though the resolution of acute symptoms seems faster in younger person, one of four may continue having symptoms 12 weeks after the onset of symptoms resulting in pain and cost to economy $[8,9]$.

A painful low back does not indicate a specific pathology but may be related to restricted, excessive, or poorly controlled lumbar motion [10-12] Altered mobility can be characterized as general (mobility of the trunk as a whole) or segmental (between two consecutive vertebra) [13]. Assessment of spinal mobility often guides the non-surgical treatment approach. For example, a patient with restricted spinal motion may receive interventions directed at improving intervertebral mobility whereas an individual with symptoms and an excessively mobile spine may receive active and/or resistive exercises to provide control of aberrant movements (i.e., "stabilization" exercises) [14].

General trunk mobility has been quantified in the clinical setting using methods of linear or angular displacement [15]. These tests, however, do not capture the existence of altered mobility at a single segment or unique patterns of aberrant segmental mobility. Clinical methods to evaluate segmental motion include manual application of a posterior to anterior (PA) force on the vertebral spinous process [16] or palpation of movement between spinous processes during flexion-extension of the trunk [16]. In both cases, the amount of motion, or resistance to force, is assessed using subjective categories of hypomobile, normal, or hypermobile. Presence, absence or change in pain resulting from the test is also noted.

It is not clear if persons with current back pain, or those with a history of frequent episodes of back pain, have altered segmental spinal mobility. Previous studies have attempted to correlate spinal mobility to clinical symptoms but have not been able to clearly establish a relationship [17-22]. Structural spine heterogeneity in the human population, age-related changes in spinal motion and experimental methodology are among just few of the confounding factors that have impeded previous attempts to establish a relationship between lumbar spine mechanics and low back pain. In addition, previous literature has focused predominantly on subjects in the middle and later stages of life, as symptoms in younger subjects are typically shorter in duration [23].

Quantity and pattern of segmental mobility may certainly vary with the type of movement tested, instructions to the subjects and their willingness to participate. For example, a self initiated test, such as a press-up (PU) maneuver may be influenced by the subject's symptoms, thereby limiting spinal segmental motion. In contrast, application of a manual PA force to a lumbar spinous process sufficient in amount to reach end-range may produce more motion since it's not self-limited by pain. Therefore, quantifying motion under these two conditions may provide a more comprehensive assessment of segmental mobility in persons with low back pain. Segmental motion of the lumbar spine during manual PA assessment has been investigated [24-27] and we are not aware of any studies that have assessed segmental mobility during a prone PU maneuver.

Using dynamic imaging techniques, the purpose of this study was to compare lumbar segmental mobility in asymptomatic and symptomatic subjects during PA spinal mobilization and a prone PU maneuver. We hypothesized that persons with central low back pain would have an altered lumbar segmental mobility pattern compared to those without pain.

\section{Methods \\ Subjects}

A total of 65 individuals between the ages of 18 and 42 participated in this study. The asymptomatic group was comprised of 20 healthy individuals, with no history of low back pain lasting more than 3 days or pain reported within the previous year (Table 1 ). The symptomatic subjects were recruited from a very busy University based general practice. Forty-five patients with non-specific central low back pain that worsened with extension, constituted the symptomatic group (Table 1). Based on the appearance of the fifth lumbar vertebrae, suggesting developmental variance one subject was excluded from further participation. An additional symptomatic subject was recruited to meet the expected subject population in this study. This analysis is a sub-protocol of a larger study thus the discrepancies in the size of the two study populations. On the day of testing, these subjects had perceived pain with standing spinal extension averaging $4.3 \pm 1.9$ on the Visual Analog Scale and their Oswestry Disability Scores range between minimal and moderate. The reported average duration of symptoms of the current episode of low back pain was 28 days. None of them were off work. Patients for whom the current episode of back pain lasted longer than 12 weeks were not included in this study.

The primary exclusion criteria for both groups were: 1) spinal malignancy, 2) cardiovascular disease, 3) evidence of cord compression, 4) aortic aneurysm, 5) hiatal hernia, 6) uncontrolled hypertension, 7) spinal infection, 8) severe respiratory disease, 9) pregnancy, 10) abdominal hernia, 11) prior low back surgery, 12) gross spinal deformity, 13) spondylolisthesis, 14) known rheumatic joint disease, and 15) implanted biological devices that could interact with the magnetic field (i.e., pacemakers, 
Table I: Anthropometric, gender and age characteristic of patients (symptomatic) and subjects (asymptomatic).

\begin{tabular}{lcccc}
\hline & \multicolumn{2}{c}{ Symptomatic } & & Asymptomatic \\
\cline { 2 - 5 } & Male $(\mathrm{N}=18)$ & Female $(\mathrm{N}=27)$ & Male $(\mathrm{N}=12)$ & Female $(\mathrm{N}=8)$ \\
\hline Age (years) & $34.1 \pm 8.6$ & $30.0 \pm 8.3$ & $30.9 \pm 6.4$ & $31.3 \pm 7.6$ \\
Body Mass $(\mathrm{kg})$ & $80.8 \pm 11.9$ & $64.2 \pm 10.4$ & $82.2 \pm 13.6$ & $57.0 \pm 5.5$ \\
Body Height $(\mathrm{cm})$ & $180.1 \pm 9.9$ & $168.9 \pm 7.2$ & $177.5 \pm 8.2$ & $167.3 \pm 4.8$ \\
\hline
\end{tabular}

cochlear implants, or ferromagnetic cerebral aneurysm clips). In addition to the above exclusion criteria, subjects in either group could not have any signs or symptoms related to nerve root or cord pathology. Therefore, subjects who demonstrated any of the following also were excluded: 1) radiating pain below the level of the buttock(s), 2) sensation changes in the lower extremities, 3) diminished reflexes, 4) lower extremity weakness, 5) urinary or fecal incontinence, and 6) increased peripheral pain with repeated lumbar extension.

\section{Instrumentation}

As described in a previous publication, [27] dynamic imaging of the lumbar spine was performed using a vertically opened (double donut design) MRI system (0.5 Tesla, Signa SP, General Electric Medical Systems, Milwaukee, WI) with a $56 \mathrm{~cm}$ opening that allowed the examiner access to the subject during testing. This system was equipped with a pulse sequence programming environment and real-time interactive MRI capability.

Midline sagittal plane imaging of the spine was performed using a receive-only surface coil and an ultrafast spoiled GRASS (gradient recalled acquisition in the steady state) pulse sequence. Images were obtained at a rate of 1 per second using the following parameters: repetition time (TR): $200 \mathrm{~ms}$; echo time (TE): $18 \mathrm{~ms}$; number of excitations: 1.0 ; matrix: $256 \times 256$; field of view (FOV): $28 \times 21$ $\mathrm{cm}$; and a $7 \mathrm{~mm}$ section thickness with an interslice spacing of $1 \mathrm{~mm}$. [27] The surface coil was flexible and designed to expose the low back such that the examiner had direct access to palpate the lumbar spinous processes.

\section{Procedure}

Prior to participation, informed consent was obtained as approved by the Institutional Review Boards of the University of Southern California and Stanford University. Two sets of images were acquired for each subject: 1) during the manual PA mobilization procedure and 2) during a PU maneuver. The order of testing was randomized for each subject.

For the PA assessments, subjects were placed in the prone position on a sliding table within the MRI system, such that the spine and torso were within the opening between the vertical magnets (Figure 1a). For each of the two procedures, the surface coil was secured to the lumbar region using cloth tape. Careful care was taken to place the coil in the same region of the subject's low back. A small pillow was positioned under the subject's abdomen, thereby mimicking the clinical procedure.

To gain an insight into the posture of the lumbar spine in the starting prone position, we measured the angular position of the lumbar curvature with an inclinometer (Universal Inclinometer, OPTP, Minneapolis, MN). To do so, we placed an inclinometer at the following anatomical locations S2, L3 and L1.

After subjects were positioned within the MRI system, a series of sagittal plane "localizers" were obtained to ensure that the image plane captured the vertebral bodies and spinous processes of all lumbar vertebrae. Once the image plane was determined, continuous imaging $(1 \mathrm{~Hz})$ commenced.

Following a static sagittal view of the lumbar spine in the resting position, a PA force was applied to the spinous processes at each vertebrae starting caudally at L5 and moving cranially to L1. The force was directed anteriorly in a direction perpendicular to the tangent of the arc of the lumbar lordosis. Sufficient force was applied to induce movement to the end of the available range of segmental motion and was comparable in magnitude to that of a "grade IV" as defined by Maitland. [16] The force was applied slowly (over approximately a 1-2 second period) and held at end range for at least five seconds. Release of the force also occurred slowly (1-2 seconds) before applying force to the next vertebral level. Once the examiner released the force on L1, and a clear resting position was observed, imaging was terminated.

All PA mobilizations were performed by a physical therapist with 15 years of manual therapy experience. A second investigator viewed the images on the MRI console to assure that the forces were being applied to the correct vertebral level. If an error was observed, imaging was repeated (this has occurred in three instances). 


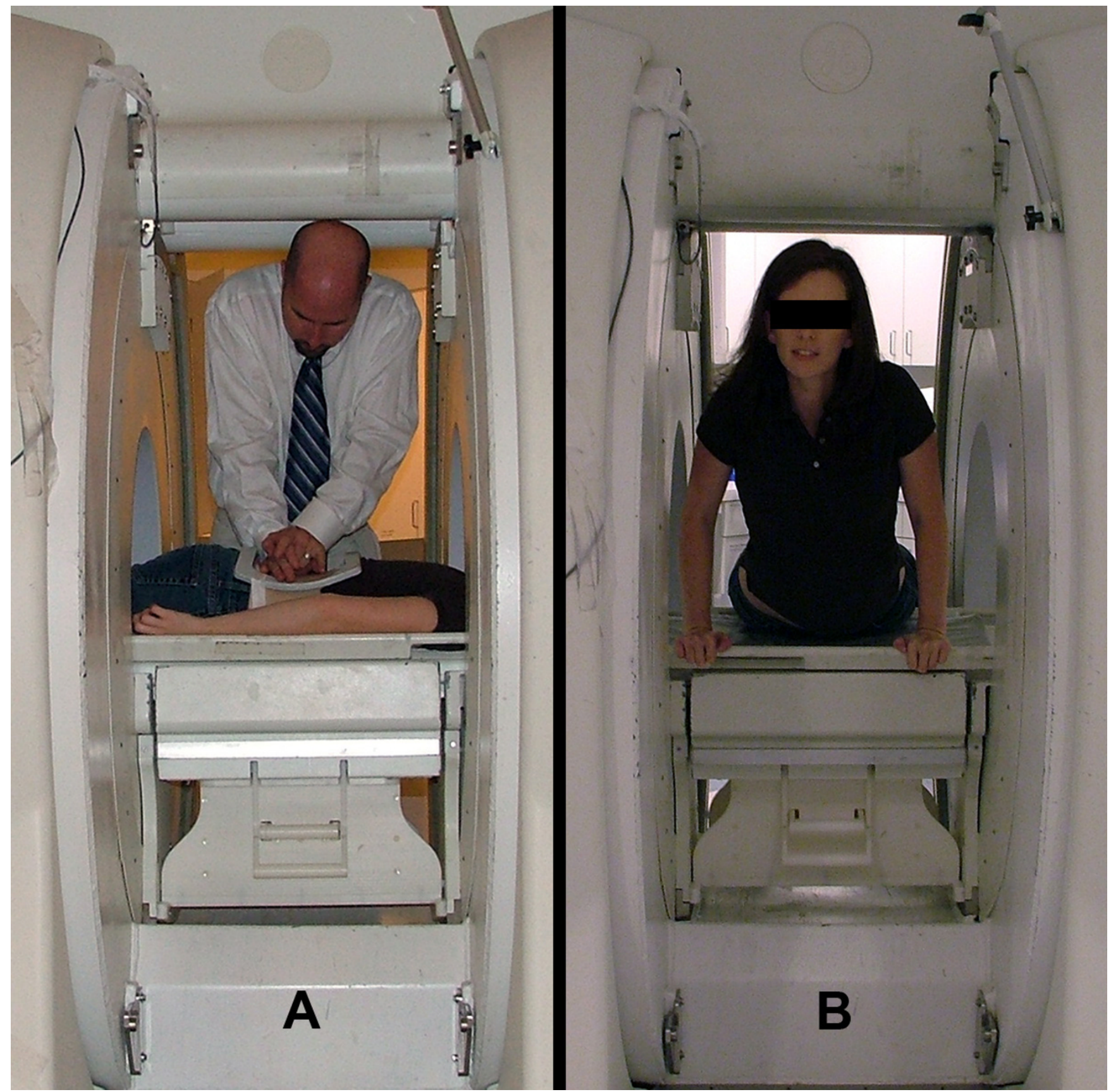

Figure I

Subject and examiner positioned within the MRI system for (a) the segmental motion of the target lumbar segment during the posterior to anterior (PA) mobilization procedure and (b) the prone press-up PU maneuver. Each subject was situated such that the spine and torso were within the opening between the vertical magnets.

For the PU assessment, subjects were placed in the prone position on the sliding table, such that the spine and torso were within the opening between the vertical magnets and the head and arms were outside of the MRI system (Figure $1 \mathrm{~b})$. For this procedure, the patient's positioning within the magnet was perpendicular to the position during the
PA mobilization testing. The surface coil was again secured to the lumbar region using cloth tape. A small pillow was positioned under the subject's abdomen for comfort. Following the subject's new positioning within the MR system, the sagittal plane "localizers" were repeated to ensure that the image plane captured the vertebral bodies 
and spinous processes of all lumbar vertebrae. Once the image plane was determined, continuous imaging $(1 \mathrm{~Hz})$ commenced. After the acquisition of a static sagittal view of the lumbar spine in the resting position, subjects placed their hands in front of them and arched their back as far as possible within pain tolerance (Figure 1b). Subjects were instructed to hold the end press-up position for a count of 10 and slowly lower the trunk to the resting position. Upon returning to the prone position, imaging was terminated.

\section{Data analysis}

Prior to analysis, all images were transferred from the MRI system console to a Macintosh G3 computer (Apple Computer, Cupertino, CA). For purposes of this study, only the images at rest and at the end-range of segmental motion were analyzed. All data sets were again screened for quality of images and for pathology. Consequently, all images were deemed appropriate for further analysis. During screening, we noticed motion artifacts in the images where motion was expected. This helped in choosing the images for analysis. As the beginning of motion was readily observable, we chose the resting image for analysis at lest 5 images before motion was observed. The end of motion image was also chosen based clarity of the images, suggesting no motion. To assure ourselves that this assumption was correct, we have randomly selected 5 studies and have digitized three consecutive images deemed to be at the end of the range. This experiment assured us that our prior choice of the final image was correct.

Lumbar segmental motion in the sagittal plane was quantified by measuring the intervertebral angle which was defined as the angle formed by lines delineating adjacent vertebral endplates (Figure 2) [27]. Segmental lumbar motion was defined as the difference between the intervertebral angles measured from the resting and the end-range images. An increase in intervertebral motion from the resting to the end-range position was indicative of spinal extension. Conversely a decrease in the intervertebral motion was indicative of spinal flexion. The superior vertebra was used to define the target functional spinal unit. For example, a PA force applied to L4 was identifying the function spinal unit of L4-L5.

The same investigator, blinded to the group assignment, made all measurements using the National Institutes of Health (NIH) software (Bethesda, MD). To establish the intra-tester reliability of angular measurements, dynamic MR images obtained from 5 healthy volunteers were measured on two separate occasions. Intraclass Correlation Coefficients (ICC) were found to be excellent, ranging from 0.95 to .99 for all subjects. The Standard Error of
Measurement was determined to be between 0.4 and 0.66 degrees.

\section{Statistical analysis}

For the PA analyses only the data from the motion-segment associated with the PA was used for the analysis. The data for both groups was screened for normality of distribution using Wilks-Shapiro $\mathrm{W}$ statistics. The symptomatic group did not exhibit normal distribution; therefore nonparametric statistics were used for further analyses.

To determine the distribution of subjects outside of the normal range of segmental mobility, the norms were established based on the asymptomatic group's mean value \pm 2 SD (see Tables 2 and 3 ). Individuals demonstrating segmental motion greater than 2 standard deviations range will be considered hypermobile while those demonstrating less than 2 standard deviations range were considered to be hypomobile. Overall frequency count will determine number of segments outside of normal range in each group of subjects. A Chi-square analyses of data at each motion- segment, comparing groups (control, symptomatic) and mobility (normal, non-normal) will be performed using SPSS statistical software (SPSS Inc., Chicago, IL) with a significance level of $p<0.05$.

\section{Results}

There was no significant difference in the starting prone position of the pelvis and the lumbar spine, between the symptomatic and asymptomatic groups. The average angular position relative to horizontal was $19.1 \pm 1.2^{\circ}$ at $\mathrm{S} 1,8.8 \pm 2.9^{\circ}$ at $\mathrm{L} 3$ and $2.3 \pm 2.6^{\circ}$ at $\mathrm{L} 1$.

The application of the PA force during the mobilization procedure resulted in extension at each targeted lumbar segment (Figure 3). The largest amount of motion occurred at L1-L2 in asymptomatic subjects $(3.9 \pm 1.7$ degrees) and at L2-L3 in symptomatic subjects $(4.3 \pm 1.5$ degrees). The least amount of motion was measured at L45 for both asymptomatic and symptomatic subjects (3.2 \pm 1.3 degrees and $3.7 \pm 1.6$ degrees, respectively).

Similar to the PA mobilization procedure, the PU maneuver resulted in extension at each segment (Figure 4). The greatest amount of motion occurred at L5-S1 in asymptomatic subjects ( $4.7 \pm 1.1$ degrees $)$ and at L4-L5 in symptomatic subjects $(4.9 \pm 1.6$ degrees $)$. The least amount of motion was measured at L1-L2 for both asymptomatic and symptomatic subjects $(3.5 \pm 1.7$ degrees and $3.8 \pm 1.9$ degrees, respectively).

The frequency analysis revealed that $40.0 \%$ of symptomatic subjects demonstrated hyper-mobility at one or more motion-segments during the PA assessment, while $26.7 \%$ of symptomatic subjects demonstrated hyper- 


\section{(a)}
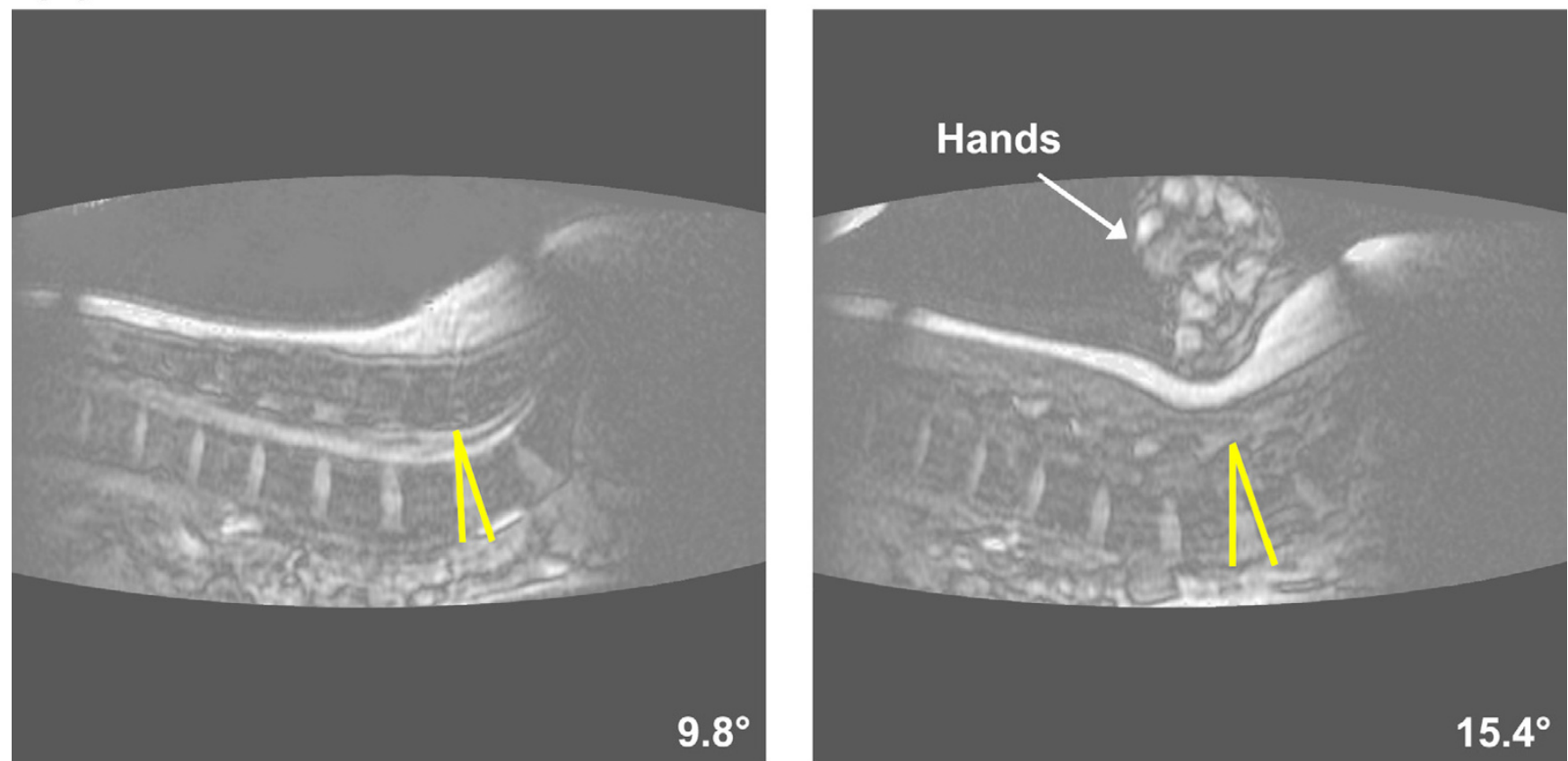

(b)
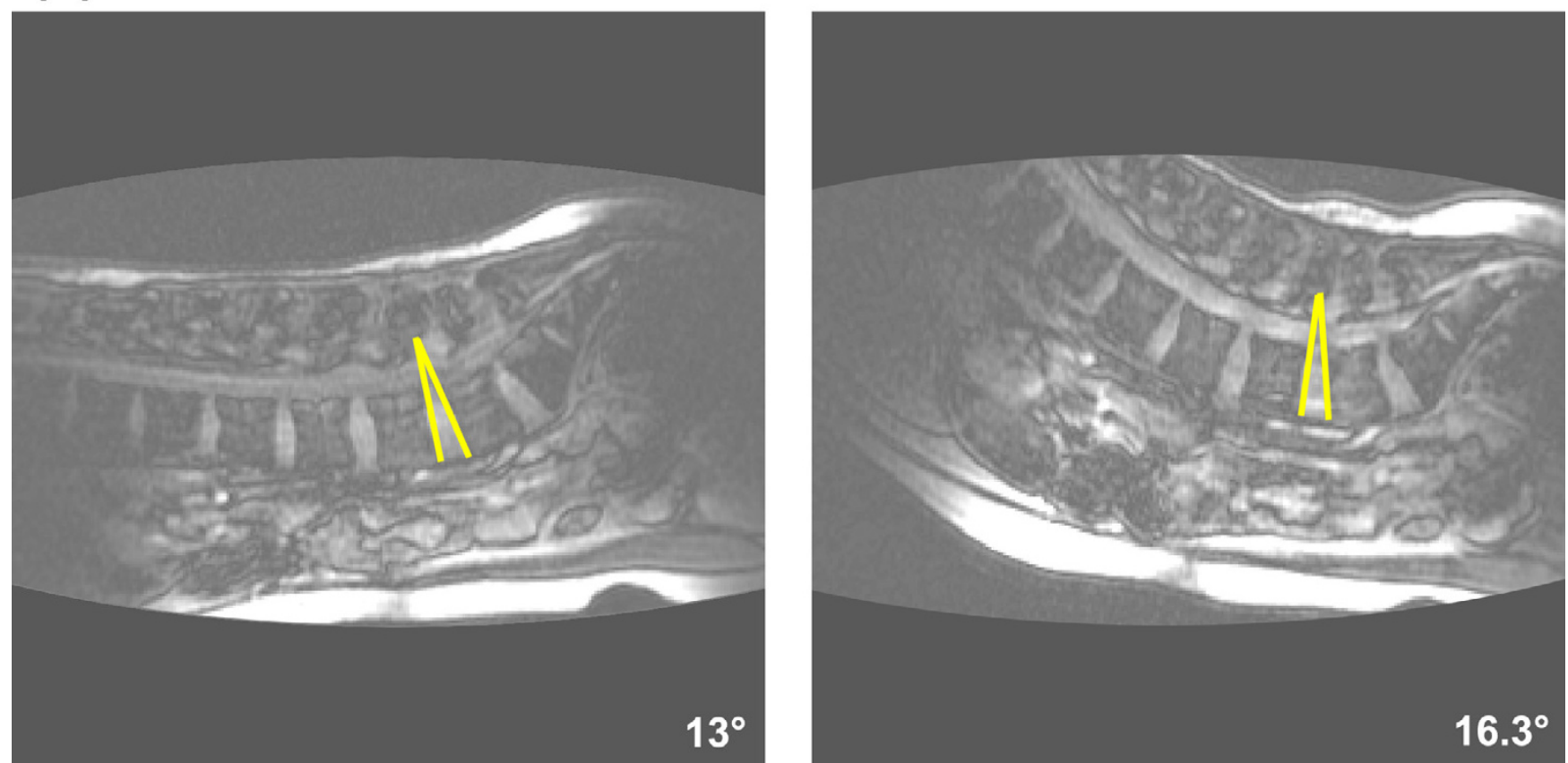

Figure 2

Measurements of intervertebral displacement resulting from the posterior to anterior (PA) mobilization and the prone pressup (PU) maneuver. The intervertebral (segmental) angle was measured as the angle formed by lines defining the endplates of adjacent vertebrae. Segmental lumbar displacement was defined as the difference in the intervertebral angle between the resting position (left) and intervertebral angle from the end range image (right). The arrow in Figure $2 \mathrm{a}$ identifies the hand of the examiner performing the PA mobilization. 
Table 2: Mean and SD of vertebral displacement (degrees), for asymptomatic subjects, resulting from the PA testing procedure (first row). Values for vertebral displacement above (second row) and below (third row) two standard deviations (2SD) from the mean of asymptomatic subjects are in bold. Number of subjects with vertebral displacement above and below two standard deviations (2SD) from the asymptomatic group mean is listed bellow. Note that I subject in the asymptomatic group and 4 in the symptomatic group exhibited vertebral displacement outside of the 2SD range.

\begin{tabular}{|c|c|c|c|c|c|c|c|}
\hline \multicolumn{2}{|l|}{ Motion-segment } & $\mathrm{LI}-\mathrm{L} 2$ & L2 - L3 & L3 - L4 & L4 - L5 & $\mathrm{L} 5-\mathrm{SI}$ & $\begin{array}{l}\text { Number of subjects with at least one level above } \\
2 \mathrm{SD} \text { or below } 2 \mathrm{SD}(\%)\end{array}$ \\
\hline \multicolumn{2}{|c|}{$\begin{array}{l}\text { Mean (SD) vertebral displacement [degrees] for } \\
\text { asymptomatic subjects }\end{array}$} & $3.7(1.4)$ & $3.8(1.4)$ & $3.5(1.7)$ & $3.2(1.3)$ & $3.6(1.1)$ & \\
\hline \multirow[t]{3}{*}{$+2 \mathrm{SD}$ [degrees] } & & 6.5 & 6.5 & 6.9 & 5.8 & 5.8 & \\
\hline & $\begin{array}{l}\text { Asymptomatic } \\
(\mathrm{N}=20)\end{array}$ & 1 & 0 & 0 & 0 & 0 & I (5\%) \\
\hline & $\begin{array}{l}\text { Symptomatic } \\
(\mathrm{N}=45)\end{array}$ & $4^{c, d}$ & $2^{c, d}$ & 2 & $4^{c}$ & 9 & $18(40 \%)$ \\
\hline \multirow{3}{*}{$-2 \mathrm{SD}$ [degrees] } & & 0.9 & 0.9 & 0.0 & 0.9 & 1.3 & \\
\hline & $\begin{array}{l}\text { Asymptomatic } \\
(\mathrm{N}=20)\end{array}$ & 0 & $\mathrm{I}^{\mathrm{a}}$ & $\mathrm{I}^{\mathrm{a}}$ & 1 & 0 & $2(10 \%)$ \\
\hline & $\begin{array}{l}\text { Symptomatic } \\
(\mathrm{N}=45)\end{array}$ & $2^{b}$ & 0 & 0 & 0 & $2^{b}$ & $2(4.4 \%)$ \\
\hline \multicolumn{5}{|l|}{ Chi- square } & $\begin{array}{l}10.0 \\
p<0.01\end{array}$ & $\begin{array}{l}4.18 \\
P<0.05\end{array}$ & \\
\hline
\end{tabular}

a includes subject 164; b includes subjects 54 and 173; c includes subject 195I; d includes subject 1955

mobility at one or more motion-segments during the PU maneuver. In contrast, only one subject (5\%) demonstrated hyper-mobility at one motion segment during the PA assessment, while 3 subjects (15\%) demonstrated hyper-mobility at one motion-segment during the PU maneuver. Individual lumbar motion-segment analysis revealed hyper-mobility in symptomatic subjects at L5 S1 (Chi-square $=10.0, \mathrm{p} \leq 0.01$ ) and L4 - L5 (Chi-square $=4.18, \mathrm{p} \leq 0.05)$ (Table 2).

The number of subjects demonstrating hypo-mobility was low in both groups. For example, during the PA assessment only $4.4 \%$ of symptomatic and $10 \%$ of asympto- matic subjects demonstrated hypo-mobility at one motion-segment. Similarly, $8.9 \%$ of symptomatic and 5\% of asymptomatic subjects demonstrated hypo-mobility at one motion-segment during the PU maneuver (Table 2 and Table 3).

\section{Discussion}

We hypothesized that there would be a difference in lumbar segmental mobility between persons with and without low back pain. We found more cases of increased lumbar segmental mobility, in subjects with low back pain than those who are pain-free, when tested manually.

Table 3: Mean and SD of vertebral displacement, for asymptomatic subjects, resulting from the PU maneuver (first row). Values for vertebral displacement above (second row) and below (third row) two standard deviations (2SD) from the mean of asymptomatic subjects are in bold. Number of subjects with vertebral displacement above and below two standard deviations (2SD) from the asymptomatic group mean is listed bellow. Note that I subject in the asymptomatic group and I in the symptomatic group exhibited motion outside of the 2SD range. There was no difference, between groups, in number of subjects exhibiting vertebral displacement outside the \pm 2 SD from the mean of the asymptomatic subjects.

\begin{tabular}{|c|c|c|c|c|c|c|}
\hline Motion-segment & $\mathrm{LI}-\mathrm{L} 2$ & L2 - L3 & L3 - L4 & L4 - L5 & $\mathrm{L} 5-\mathrm{SI}$ & $\begin{array}{l}\text { Number of subjects with at least one level above } \\
2 \mathrm{SD} \text { or below } 2 \mathrm{SD}(\%)\end{array}$ \\
\hline $\begin{array}{l}\text { Mean (SD) segmental motion [degrees] for } \\
\text { asymptomatic subjects }\end{array}$ & $3.4(1.6)$ & $4.1(2.5)$ & $4.6(2.2)$ & $4.1(1.9)$ & $4.7(2.3)$ & \\
\hline$+2 \mathrm{SD}$ [degrees] & 6.6 & 9.1 & 9.0 & 7.9 & 9.3 & \\
\hline $\begin{array}{l}\text { Asymptomatic } \\
(\mathrm{N}=20)\end{array}$ & 0 & $2^{\mathrm{a}}$ & 0 & $\mathrm{I}^{\mathrm{a}}$ & 1 & $3(15 \%)$ \\
\hline $\begin{array}{l}\text { Symptomatic } \\
(N=45)\end{array}$ & $5^{b}$ & $\mathrm{Ib}^{\mathrm{b}}$ & 0 & 5 & 2 & $12(26.7 \%)$ \\
\hline$-2 \mathrm{SD}$ [degrees] & 0.2 & -0.9 & 0.4 & 0.3 & 0.1 & \\
\hline $\begin{array}{l}\text { Asymptomatic } \\
(\mathrm{N}=20)\end{array}$ & 0 & 0 & 0 & 1 & 0 & I (5\%) \\
\hline $\begin{array}{l}\text { Symptomatic } \\
(N=45)\end{array}$ & 1 & 0 & 2 & 0 & 1 & $4(8.9 \%)$ \\
\hline
\end{tabular}

a includes subject 1891 ; $b$ includes subjects 2012 


\section{Location of PA Force Applied:}

$\begin{array}{lllll}\text { L1 } & \text { L2 } & \text { L3 } & \text { L4 } & \text { L5 }\end{array}$

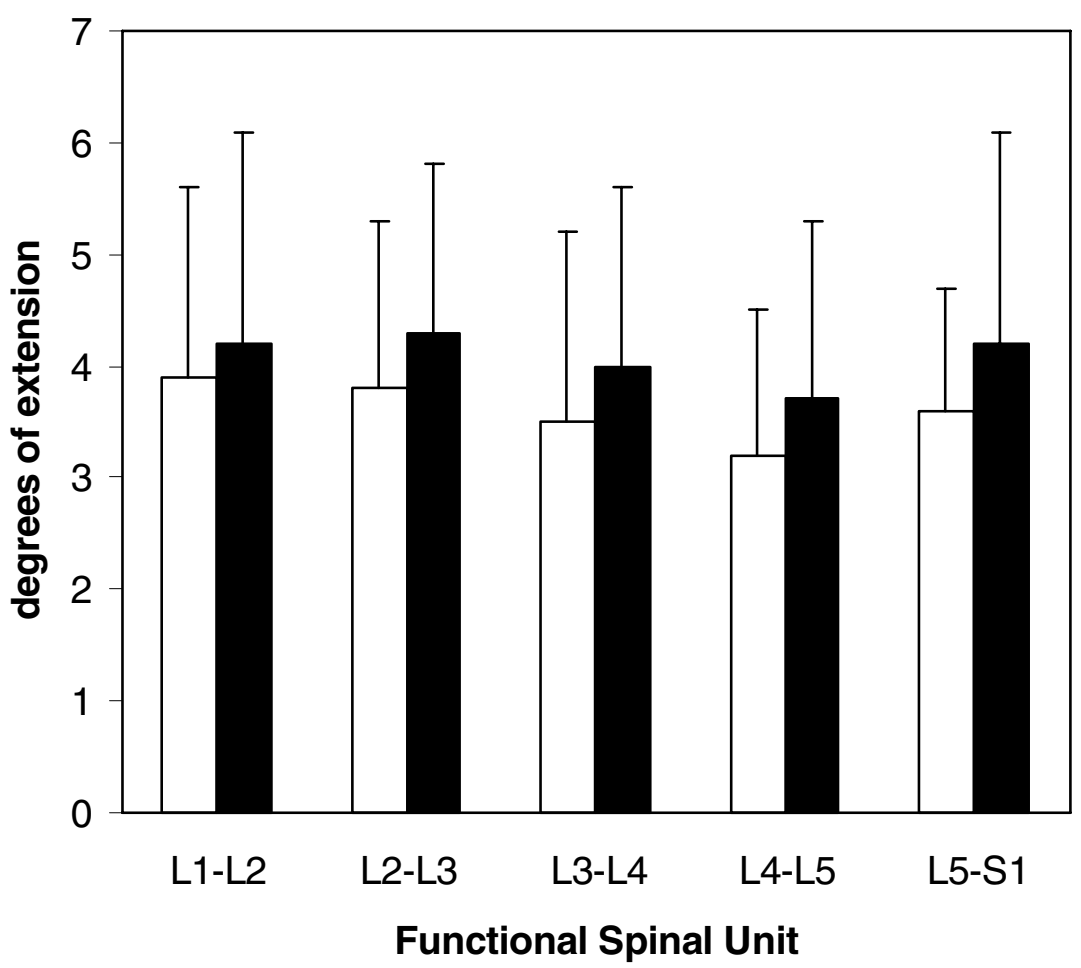

Asymptomatic $\mathbf{\text { Symptomatic }}$

Figure 3

Mean segmental motion of the target lumbar segment during the posterior to anterior (PA) mobilization procedure. Error bars represent I SD.

These hyper-mobilities were observed at the L4-L5 and L5S1 motion-segments.

The highest incidence of hypermobility in the symptomatic group was observed at L5-S1 during the PA procedure and at L4-L5 during the PU. When the frequencies of hypermobility at L5-S1 and L4-L5 were combined, they constituted $56.5 \%$ and $66.7 \%$ of all levels for the PA and PU procedures, respectively. This analysis suggests that a relatively high percentage of subjects in the symptomatic group demonstrated tendency towards hypermobility, especially at the L4-L5 and L5-S1 motion-segments. The tendency towards segmental hypermobility in our young symptomatic subjects is similar to that identified by Dvorak et al [28].

The quantities of intervertebral motions imparted by the two tests were different. Overall, the PU test produced slightly more movement at four of the five motion-segments than the PA test. Suggesting, that the subjects were willing to extend their back and pain was not limiting their lumbar extension in the prone position. Interestingly, it was not the self-administered PU test, but the manual PA test, that identified the hypermobile segments. It is possible that the participants were able to control the motion during the PU maneuver and the PA imparted the intervertebral motion passively. This observation suggests that the PA procedure allows for identifying hypermobilities.

Increased motion (hyper-mobility) can be linked with recent disc injury, early disc degeneration or skeletal trauma. Subjects with skeletal trauma were excluded from this study. Hence relating intervertebral mobility to the condition of the disc is reasonable. As the mean age of the subjects in our study was in the early thirties, it is likely that their intervertebral discs were relatively normal, or at the very least, in the early stages of degeneration. The general trends in later life are associated with further disc degeneration and consequent joint degenerations leading 


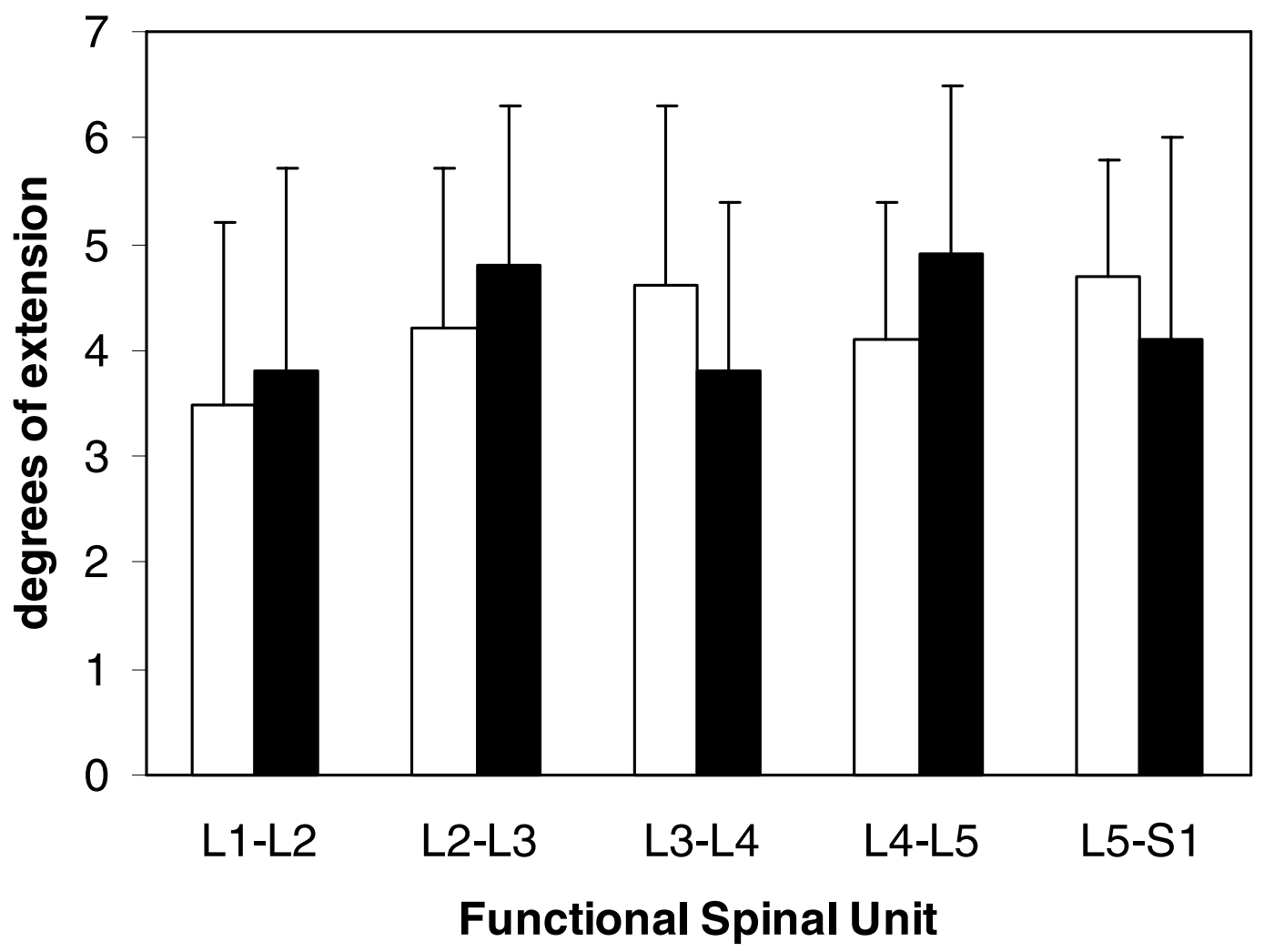

\section{$\square$ Asymptomatic $\square$ Symptomatic}

Figure 4

Mean segmental motion of the lumbar segments during the prone press-up (PU) maneuver. Error bars represent I SD.

to decreased motion (hypo-mobility). Therefore, the age of the subjects in this study may have had an influence on measured segmental mobility.

The observation made from this study need to be viewed within its limitations. We relied on the experience of the operator (physical therapist) to apply sufficient about of force to produce end range at a motion-segment. We might have had introduced systematic bias into the PA experiment, by applying force from caudal to cranial, instead of randomizing the location of the force application. We studied a limited age range and are not able to compare between younger and older age groups.

\section{Conclusion}

This study quantified in vivo segmental spinal mobility during a PA mobilization procedure and during a prone PU maneuver in persons with and without low back pain. The PA procedure identified hypermobilities at the L4-L5 and L5-S1 motion segments in the symptomatic group.

\section{Completing interests}

The author(s) declare that they have no competing interests.

\section{Authors' contributions}

$\mathrm{KK}, \mathrm{CMP}$, and RFL were responsible for the design of this study. CMP secured funding for this study. HW performed the data processing and analysis. MF and MG contributed to data collection and data interpretation. KB provided MRI expertise.

All authors read and approved the final manuscript.

\section{Acknowledgements}

Protocol was reviewed and approved by the Institutional Review Boards of the University of Southern California and Stanford University.

Research supported by Foundation for Physical Therapy. 


\section{References}

I. Guzman J, Esmail R, Karjalainen K, Malmivaara A, Irvin E, Bombardier C: Multidisciplinary bio-psycho-social rehabilitation for chronic low back pain. Cochrane Database Syst Rev 2002:CD000963.

2. Nickel R, Egle UT, Eysel P, Rompe JD, Zollner J, Hoffmann SO: Health-related quality of life and somatization in patients with long-term low back pain: a prospective study with 109 patients. Spine 200I, 26(20):227I-2277.

3. Scientific approach to the assessment and management of activity-related spinal disorders. A monograph for clinicians. Report of the Quebec Task Force on Spinal Disorders. Spine I 987, I 2(7 Suppl):SI-59.

4. Frank JW, Kerr MS, Brooker AS, DeMaio SE, Maetzel A, Shannon HS, Sullivan TJ, Norman RW, Wells RP: Disability resulting from occupational low back pain. Part I: What do we know about primary prevention? A review of the scientific evidence on prevention before disability begins. Spine 1996, 2I(24):2908-29I7.

5. Frank JW, Brooker AS, DeMaio SE, Kerr MS, Maetzel A, Shannon HS, Sullivan TJ, Norman RW, Wells RP: Disability resulting from occupational low back pain. Part II: What do we know about secondary prevention? A review of the scientific evidence on prevention after disability begins. Spine 1996, 2 I (24):2918-2929.

6. Volinn E: The epidemiology of low back pain in the rest of the world. A review of surveys in low- and middle-income countries. Spine 1997, 22(15): I747-1754.

7. Walker BF: The prevalence of low back pain: a systematic review of the literature from 1966 to 1998 . J SPINAL DISORD 2000, I3(3):205-217.

8. McBride D, Begg D, Herbison P, Buckingham K: Low back pain in young New Zealanders. N Z Med J 2004, I I 7(I 203):UI099.

9. Grotle M, Brox JI, Veierod MB, Glomsrod B, Lonn JH, Vollestad NK: Clinical course and prognostic factors in acute low back pain: patients consulting primary care for the first time. Spine 2005, 30(8):976-982.

10. Abbott JH, Fritz JM, McCane B, Shultz B, Herbison P, Lyons B, Stefanko $G$, Walsh RM: Lumbar segmental mobility disorders: comparison of two methods of defining abnormal displacement kinematics in a cohort of patients with non-specific mechanical low back pain. BMC musculoskeletal disorders [electronic resource] 2006, 7:45.

I I. Mayer TG, Robinson R, Pegues P, Kohles S, Gatchel RJ: Lumbar segmental rigidity: can its identification with facet injections and stretching exercises be useful? Archives of physical medicine and rehabilitation 2000, 8 I(9): I |43- I I50.

12. Panjabi MM: Clinical spinal instability and low back pain. J Electromyogr Kinesiol 2003, I 3(4):371-379.

13. Hicks GE, Fritz JM, Delitto A, Mishock J: Interrater reliability of clinical examination measures for identification of lumbar segmental instability. Archives of physical medicine and rehabilitation 2003, 84( I 2): | 858-1864.

14. Hicks GE, Fritz JM, Delitto A, McGill SM: Preliminary development of a clinical prediction rule for determining which patients with low back pain will respond to a stabilization exercise program. Archives of physical medicine and rehabilitation 2005, 86(9): I753-1762.

15. Macrae IF, Wright V: Measurement of lumbar spine motion in population studies. Ann Rheum Dis 1969, 28(3):329.

16. Maitland GD Hengeveld, E., Banks, K., English, K.: Vertebral Manipulation. 6th edition. London, Butterworth-Heinemann; 2001.

17. Bjornsdottir SV, Kumar S: Posteroanterior spinal mobilization: state of the art review and discussion. Disabil Rehabil 1997, I 9(2):39-46.

18. Burton AK, Battie MC, Gibbons L, Videman T, Tillotson KM: Lumbar disc degeneration and sagittal flexibility. J SPINAL DISORD 1996, 9(5):418-424.

19. Burton AK, Tillotson KM, Edwards VA, Sykes DA: Lumbar sagittal mobility and low back symptoms in patients treated with manipulation. J SPINAL DISORD 1990, 3(3):262-268.

20. Latimer J, Lee M, Adams R, Moran CM: An investigation of the relationship between low back pain and lumbar posteroanterior stiffness. J Manipulative Physiol Ther 1996, I 9(9):587-59I.
21. Thompson RE, Pearcy MJ, Downing KJ, Manthey BA, Parkinson IH, Fazzalari NL: Disc lesions and the mechanics of the intervertebral joint complex. Spine 2000, 25(23):3026-3035.

22. Twomey LT: A rationale for the treatment of back pain and joint pain by manual therapy. Phys Ther 1992, 72(12):885-892.

23. van Tulder MW, Koes BW, Bouter LM: Conservative treatment of acute and chronic nonspecific low back pain. A systematic review of randomized controlled trials of the most common interventions. Spine 1997, 22(I8):2128-2I56.

24. Beneck GJ, Kulig K, Landel RF, Powers CM: The relationship between lumbar segmental motion and pain response produced by a posterior-to-anterior force in persons with nonspecific low back pain. J Orthop Sports Phys Ther 2005, 35(4):203-209.

25. Kulig K, Landel R, Powers CM: Assessment of lumbar spine kinematics using dynamic MRI: a proposed mechanism of sagittal plane motion induced by manual posterior-to-anterior mobilization. J Orthop Sports Phys Ther 2004, 34(2):57-64.

26. Lee $R$, Evans J: An in vivo study of the intervertebral movements produced by posteroanterior mobilization. Clin Biomech 1997, I 2(6):400-408.

27. Powers CM, Kulig K, Harrison J, Bergman G: Segmental mobility of the lumbar spine during a posterior to anterior mobilization: assessment using dynamic MRI. Clin Biomech (Bristol, Avon) 2003, I 8(I):80-83.

28. Dvorak J, Panjabi MM, Novotny JE, Chang DG, Grob D: Clinical validation of functional flexion-extension roentgenograms of the lumbar spine. Spine I99I, I 6(8):943-950.

\section{Pre-publication history}

The pre-publication history for this paper can be accessed here:

http://www.biomedcentral.com/1471-2474/8/8/prepub
Publish with Bio Med Central and every scientist can read your work free of charge

"BioMed Central will be the most significant development for disseminating the results of biomedical research in our lifetime. "

Sir Paul Nurse, Cancer Research UK

Your research papers will be:

- available free of charge to the entire biomedical community

- peer reviewed and published immediately upon acceptance

- cited in PubMed and archived on PubMed Central

- yours - you keep the copyright

Submit your manuscript here:

http://www.biomedcentral.com/info/publishing_adv.asp
BioMedcentral 